\title{
Erratum to: Why the Boys are Missing: Using Social Capital to Explain Gender Differences in College Enrollment for Public High School Students
}

\author{
Sarah Klevan $^{1} \cdot$ Sharon L. Weinberg ${ }^{1} \cdot$ Joel A. Middleton $^{2}$
}

Published online: 12 November 2015

(C) Springer Science+Business Media New York 2015

\section{Erratum to: Res High Educ \\ DOI: $10.1007 / \mathrm{s} 11162-015-9384-9$}

In the original publication, in two instances (in the abstract and the discussion) numerical results were submitted and published incorrectly.

In the abstract, the published version of the article reads:

In particular, we show that social capital reduces the odds ratio of women enrolling in college compared to men from 1.63 to 1.41 . We show also that when grade point average is added to social capital, the odds ratio reduces from 1.41 to 1.23 , showing that a substantial amount, but not all, of the gender disparity in college enrollment can be explained by these factors.

The correct statement reads:

In particular, we show that social capital reduces the odds ratio of women enrolling in college compared to men from 1.64 to 1.48 . We show also that when grade point average is added to social capital, the odds ratio reduces from 1.48 to 1.21 , showing that a substantial amount, but not all, of the gender disparity in college enrollment can be explained by these factors.

The online version of the original article can be found under doi:10.1007/s11162-015-9384-9.

Sarah Klevan

slk342@nyu.edu; sarah.klevan@nyu.edu

Sharon L. Weinberg

sharon.weinberg@nyu.edu

Joel A. Middleton

joel.middleton@berkeley.edu

1 New York University, New York, NY, USA

2 University of California, Berkeley, Berkeley, CA, USA 
In the discussion, the published version of the article reads:

The significance of our results suggests that the intersection between gender, social capital, and grade point average contributes needed complexity to the understanding of the gender inequality in college enrollment. We started by observing a substantial difference in girls and boys odds of enrolling in college $(\mathrm{OR}=1.63)$. By adding social capital variables to our model we explained a substantial (and statistically significant) part of the gender difference in college enrollment, reducing the odds ratio from 1.63 to 1.41 . By adding grade point average to the equation in Model 3 there is an additional drop in the girls to boys college enrollment odds ratio (from 1.41 to 1.23 ).

The correct statement reads:

The significance of our results suggests that the intersection between gender, social capital, and grade point average contributes needed complexity to the understanding of the gender inequality in college enrollment. We started by observing a substantial difference in girls and boys odds of enrolling in college $(\mathrm{OR}=1.64)$. By adding social capital variables to our model we explained a substantial (and statistically significant) part of the gender difference in college enrollment, reducing the odds ratio from 1.64 to 1.48 . By adding grade point average to the equation in Model 3 there is an additional drop in the girls to boys college enrollment odds ratio (from 1.48 to 1.21 ). 